\title{
Why Is the Equal Merit Principle (Almost) Straightforwardly Wrong?
}

\section{Tamas Gyorfi*}

Wordcount: 11105 including footnotes/9520 excluding footnotes

Keywords:

Judicial appointments, merit in judicial appointments, equal merit, judicial diversity, Constitutional Reform Act 2005, Crime and Courts Act 2013

\begin{abstract}
:
This article challenges the 'Equal Merit Principle', introduced to the judicial appointment process by the Crime and Courts Act 2013. The author argues that this principle does not take diversity seriously enough and none of its possible justifications stand up to close scrutiny. The author also claims that the doctrine that judges should be appointed solely on the basis of merit is either wrong, for the very same reasons as the Equal Merit Principle, or rather uninformative because it fails to give sufficient guidance to those who select judges.
\end{abstract}

\footnotetext{
* Senior Lecturer, University of Aberdeen. The author would like to thank Abbe Brown and Alan Paterson for their helpful comments. Any remaining errors are the responsibility of the author. All websites cited were last accessed on 15 December 2016.
} 


\section{Introduction}

It is commonplace that the UK Supreme Court (previously the Appellate Committee of the House of Lords) is less diverse than the highest courts of most Western democracies. ${ }^{1}$ The typical judge of the Court is a white, heterosexual male from an upper middle-class background, and was privately educated and graduated from Oxford or Cambridge. The professional background of the justices also shows a fairly consistent pattern. Most of them come from a small number of commercial chambers based in London. ${ }^{2}$ By the 1990 s this homogeneity 'had become the subject of growing concern as the lack of diversity in the make-up of the Court increasingly stood in contrast to the changing composition of many other public institutions. ${ }^{3}$

Since then the judicial appointment process has undergone a major change. The Constitutional Reform Act 2005 (hereafter CRA) has replaced the old 'tapping on the shoulder' method of appointment with a transparent and open process. Increasing diversity has become one of the declared objectives of the legal system ${ }^{4}$ and the issue has attracted serious attention from lawyers, academics and politicians alike. ${ }^{5}$ Today, there is a lively public debate about how the judiciary can be made more diverse ${ }^{6}$ The Judicial Appointments

\footnotetext{
${ }^{1}$ For comparative data, see C. Thomas, 'Judicial Diversity in the United Kingdom and Other Jurisdictions' (2005) <https://www.ucl.ac.uk/laws/judicialinstitute/files/Judicial_Diversity_in_the_UK_and_other_jurisdictions.pdf>; A. Paterson and C. Paterson, 'Guarding the Guardians? Towards an Independent, Accountable and Diverse Senior Judiciary' (2012) <https://pure.strath.ac.uk/portal/files/14551390/guarding_the_guardians.pdf>; P.H. Russell and K. Malleson (eds), Appointing Judges in an Age of Judicial Power: Critical Perspectives from around the World (Toronto: University of Toronto Press 2006).

${ }^{2}$ For the social and professional makeup of the Appellate Committee of the House of Lords, see Kate Malleson, 'Appointments to the House of Lords: Who Goes Upstairs' in L. Blom-Cooper, B. Dickson and G. Drewry (eds), The Judicial House of Lords: 1876-2009 (Oxford: OUP 2009).

${ }^{3}$ ibid, 114.

${ }^{4}$ For a recent view on the issue, see 'UK's top judge unveils plan to make supreme court more diverse.' Guardian, 21 November 2016. <https://www.theguardian.com/law/2016/nov/21/lord-neuberger-uks-top-judgeunveils-supreme-court-diversity-plan-retirement $>$.

${ }^{5}$ For a detailed survey of the debate, see Annex iii to the 'The Report of the Advisory Panel on Judicial Diversity 2010'<https://www.ucl.ac.uk/laws/judicialinstitute/files/Report_of the Advisory_Panel_on_Judicial_Diversity.pdf $>$.

${ }^{6}$ See, for instance, House of Lords Select Committee on the Constitution, 'Judicial Appointments' 25th Report
} 
Commission (hereinafter JAC) has both a statutory duty and a well-defined action plan to encourage diversity. ${ }^{7}$ Access to regularly updated data on the make-up of the judiciary is freely available and makes the monitoring of appointments possible. As a result of these efforts, the British judiciary has become more diverse than it was before. ${ }^{8}$

As part of these developments, the Crime and Courts Act 2013 has introduced a new element into the selection process, the so-called Equal Merit Principle. Although judges should be selected 'solely on merit", if two candidates have equal merit, this process allows the selecting body to prefer one of them over the other for the purpose of increasing diversity. ${ }^{10}$

The aim of this paper is not to assess the success or failure of all these efforts to advance diversity. ${ }^{11}$ More generally, I do not tackle the practical question of how the judiciary can be made more diverse. Instead, I focus on the theoretical question of how much diversity is desirable. I will specifically challenge the Equal Merit Principle and argue that it does not take diversity seriously enough and none of the possible justifications of the principle stand up to close scrutiny. I also claim that the 'Solely on Merit Principle' is either wrong, for the very same reasons as the Equal Merit Principle, or rather uninformative since it fails to give sufficient guidance to those who select judges.

The rest of this introduction makes some preliminary points, while the remaining part of the paper is divided into three sections. The next section distinguishes three possible readings of the Equal Merit Principle and argues that none of them are able to make the principle attractive. After that, I challenge an alternative argumentative strategy developed

\footnotetext{
(2010-12) http://www.publications.parliament.uk/pa/ld201012/ldselect/ldconst/272/272.pdf.

7 'Judicial Appointments Commission - Diversity Strategy' <https://jac.judiciary.gov.uk/diversity-strategy >

8 'Judicial Diversity Statistics 2016' <https://www.judiciary.gov.uk/wp-content/uploads/2016/07/judicialdiversity-statistics-2016-2.pdf>.

${ }^{9}$ CRA s 63(2). Supreme Court justices must be appointed on merit. s 27(5).

${ }^{10}$ CRA ss 63(4), 27(5A)(b)

${ }^{11}$ See, for instance, K. Malleson, 'Diversity in the Judiciary: The Case For Positive Action' (2009) 36 Journal of Law and Society 376; L. Barmes and K. Malleson, 'The Legal Profession as Gatekeeper to the Judiciary: Design Faults in Measures to Enhance Diversity’ (2011) 74 MLR 245.
} 
most skilfully by Erika Rackley, which aims to eliminate the conflict between merit and diversity. In the final section, I address some potential objections to my position and fine-tune the main argument of the paper by introducing a few qualifications.

In the course of my analysis, I will set aside two possible objections to the Equal Merit Principle. First, some scholars have argued that merit is so subjective that it is impossible to use it as a selection criterion. ${ }^{12}$ If correct, this argument challenges not only the Equal Merit Principle but the very possibility of a merit-based appointment system. The point is not that we do not have even a rough consensus on what merit means - the problem is rather that merit is a multidimensional concept. It has different aspects and reasonable people will disagree on how much weight should be assigned to each of those aspects. ${ }^{13}$ For example, the criteria that were developed by the JAC include both intellectual capacity and communication skills. We can agree that both attributes are important but might disagree on how we should balance them. Even though such an objection is certainly reasonable, once we commit ourselves to a particular (not necessarily the only reasonable) weighted balance of the components of merit, the criteria settled on can be in principle consistently applied to all individual cases.

The second objection is more limited since it does not challenge the very idea of a merit-based system; instead, it targets specifically the Equal Merit Principle. It says that two candidates cannot have equal merit because if we dig deep enough, we will always find something that differentiates two candidates. If the decision-makers had infinite time and scrutinised only two candidates, they could probably spot some difference. However, when a multi-member institution evaluates many candidates, the selection exercise might result in a tie and time-constraints might make further scrutiny practically impossible. The Report of the

\footnotetext{
${ }^{12}$ D. Roithmayr, 'Deconstructing the Distinction between Bias and Merit' (1997) 85 California Law Review 1449; R. Delgado, 'Rodrigo's Tenth Chronicle: Merit and Affirmative Action' (1994) 83 Georgia Law Journal 1711.

${ }^{13}$ See $n 6$ above, [86].
} 
House of Lords Select Committee itself addresses this issue: 'It seems likely that in large assessment exercises it would not always be possible to rank every candidate in strict order of merit and that a number of candidates may be considered to be of equal merit. ${ }^{, 14}$

As a final preliminary note, it is worth keeping in mind that diversity has not only various justifications but also different forms. It is important to note from the outset that my argument is primarily about cognitive diversity. Each individual has a distinctive cognitive toolkit that comprises concepts through which the individual perceives and interprets the world, heuristics that help them to solve problems and predictive models that enable them to predict future events and outcomes. ${ }^{15}$ The more tools in the toolkit of a certain group, the more diverse the group is from a cognitive perspective. Social diversity (the social make-up of a group) is analytically distinct from cognitive diversity. ${ }^{16}$ However, I will assume that there is a correlation between the two forms of diversity. People with different social background have different experiences that shape how they perceive the world and what kinds of cognitive tools they have. Because of this correlation, I will usually use the term diversity in this paper without any adjectives, even though I am aware of the conceptual distinction between cognitive and social diversity.

\section{The Critique of the Equal Merit Principle}

\section{Challenging the Equal Merit Principle}

The Equal Merit Principle is highly plausible at face value. Actually, it seems so uncontroversial that we do not usually require any further justification for it. This might explain why once we challenge the principle, we find that it is not only vulnerable to many

\footnotetext{
14 ibid, [99].

${ }^{15}$ Here I draw on S.E. Page, The Difference: How the Power of Diversity Creates Better Groups, Firms, Schools, and Societies (Princeton: Princeton University Press 2008) 22.

${ }^{16}$ For an analogous distinction between explicit and tacit diversity, see R.J. Cahill-O'Callaghan, 'Reframing the Judicial Diversity Debate: Personal Values and Tacit Diversity’ (2015) 35 Legal Studies 1.
} 
objections but also unsupported by robust arguments. I contend that to be successful, the advocates of the principle should establish any of the following three premises: (1) diversity is not an epistemic asset; (2) even if diversity is an epistemic asset, no trade-off between diversity and merit can ever be justified; (3) merit should always trump diversity, even if it makes the epistemic performance of courts suboptimal. What is really striking is that the proponents of the principle do not provide robust arguments for any of the aforementioned three theses.

The claim that appointment must be based solely on merit seems almost tautological. According to the Oxford English Dictionary, merit is 'the quality of being particularly good or worthy, especially so as to deserve praise or reward.' Attributing merit to a candidate is not a neutral description of the candidate's qualities but a coupling of this description with a moral judgment concerning whether the candidate deserves to be appointed. The proposition that a non-meritorious or the less meritorious candidate should be appointed seems to suggest either cynicism or a fundamental misunderstanding of the nature of the selection exercise. All this is reflected in the House of Lords Select Committee's report that states: 'It is axiomatic that judges must be appointed on merit [emphasis mine]. ${ }^{, 17}$

We can only make progress in the analysis if we decouple the characterisation of the candidate's qualities (this is itself an evaluative exercise) from the judgment of whether the candidate in question deserves to be appointed. For that purpose, let me replace the morallyladen concept of merit with the more neutral concept of competence (let us stipulate that competence encompasses all the criteria of merit developed by the $\mathrm{JAC}^{18}$ ) and suspend judgment on whether the most competent candidate deserves to be appointed. Decoupling the question of judicial competence from the final judgement on who should be appointed forces us to articulate the unstated assumption of the argument and explain why and how much

\footnotetext{
${ }^{17}$ See $\mathrm{n} 6$ above, [83].

${ }^{18}$ According to the JAC, merit has five main components: intellectual capacity, personal qualities, an ability to understand and deal fairly, authority and communication skills, efficiency.
} 
competence matters.

\section{Diversity has no epistemic value}

My contention is that the Equal Merit Principle has three possible justifications. I will address them in turn and conclude that none of them hold water. Let me call the first view that provides the most straightforward explanation of the principle the simple view on judicial appointments. The simple view has four tenets: (1) The judicial appointment process has to maximise the epistemic performance of courts; (2) Non-epistemic considerations should play a role in the process only as tiebreakers, and should not be balanced against epistemic considerations; (3) Diversity is not an epistemic asset; (4) Competence is the only epistemically relevant consideration, therefore, the maximisation of competence maximises the epistemic performance of courts. Let me spell out these claims in more detail.

As I said, once we give up the view that the Solely on Merit Principle is axiomatic, we must articulate why competence matters. The simple view answers this question by referring to the epistemic performance of courts: courts as institutions have to be able to collect and process information, interpret legal rules and principles, analyse legal concepts, and assess legal arguments. As a society, we expect courts to make good decisions. We very often disagree on what constitutes a good decision in a particular case. However, for the purposes of the argument, we do not have to agree on what constitutes a good decision in every single case; it is sufficient to agree on the assumption that a more competent judiciary will generally make better decisions than a less competent one. ${ }^{19}$ According to the simple view, competence is important for instrumental reasons: a judiciary with more competent judges will be more likely to produce better decisions. Let us call this first tenet of the simply

\footnotetext{
${ }^{19}$ For a more detailed explanation of how we can judge the epistemic credentials of an institution without agreeing on the correctness of particular decisions made by the institution, see A. Vermeule, Law and the Limits of Reason (Oxford: OUP 2009) 8.
} 
view the Performance Maximising Principle.

The second tenet of the simple view is that epistemic performance is not only $a$ relevant concern but the most important consideration. The selection process, therefore, can take into account other reasons only when we run out of epistemic considerations. If, $e x$ hypothesi, we cannot make a decision on epistemic grounds, but we have to make a decision anyway, we can rely on some other form of consideration.

For the purposes of my critique, the third tenet of the simple view is crucial. The advocates of the simple view are certainly correct to emphasise that we often use nonepistemic arguments to advance diversity. It is not unreasonable to think that if the judiciary is not diverse enough, many people will perceive it as a body that reflects the views of and protects the interests of a narrow elite, and that cannot possibly understand their concerns. People will accept judicial decisions more easily and respect them more if judges are in a meaningful sense like them. Let us call this the argument from public confidence.

Second, one could argue that diversity is important not because of how the public, in general, perceives the judiciary, but because it is what justice to individual candidates requires. From here, the argument can take two forms. According to the first version of the argument, since talent is distributed roughly evenly in society, the current allocation of judicial offices is certainly unjust. For instance, female judges can be just as good as male judges, so the fact that they are significantly underrepresented in the higher echelons of the judiciary can be explained only by the injustice of the system. If women had an equal opportunity to become judges, so the argument runs, the number of male and female judges would be roughly the same. This argument suggests that we should reach out to formerly underrepresented groups, but the selection must be made solely on competence. As the Report of the Advisory Panel on Judicial Diversity puts it: 'You should not be looking for 
unusual talent, but looking for talent in unusual places. ${ }^{20}$ Although this position certainly has merit, it does not help me test the Equal Merit Principle; rather, it only gives us guidance on how we can maximise competence but says nothing about whether a trade-off between competence and diversity can ever be justified.

The second version of the equal opportunity argument suggests that equal opportunity requires more than reaching out to formerly underrepresented groups and broadening the pool of candidates. Since certain groups were systematically excluded from judicial offices in the past, they deserve to be appointed, even if that means that, at least temporarily, not always the most competent candidate will be appointed..$^{21}$

I will not discuss the merits of these arguments. For us, the crux of the question is not whether there are cogent non-epistemic reasons for diversity, but whether diversity is also important for epistemic reasons. One could expect that the simple view has well-articulated and robust reasons to substantiate its third tenet that answers the question in the negative. But this is not the case. Actually, the simple view flies in the face of a fairly solid expert consensus. Both the Report of the Advisory Panel on Judicial Diversity ${ }^{22}$ and the Report of the House of Lords Select Committee on the Constitution, ${ }^{23}$ drawing on the expertise of leading academics and judges, conclude that diversity does have epistemic relevance. ${ }^{24}$ The latter states that 'Judging is a complex activity: it is necessary for judges to understand the wide array of concerns and experiences of those appearing before them. A more diverse judiciary can bring different perspectives to bear on the development of the law and to the

\footnotetext{
${ }^{20} \mathrm{n} 5$ above, [23].

${ }^{21}$ For an overview of the different forms of affirmative action, see K. Malleson, 'Rethinking the Merit Principle in Judicial Selection' (2006) 33 Journal of Law and Society 126, 130-135; K. Malleson, 'Diversity in the Judiciary: The Case For Positive Action' n 10 above, 393-397. For an additional line of non-epistemic argument, see D. B. Wilkins, "From" Separate Is Inherently Unequal” to" Diversity Is Good for Business": The Rise of Market-Based Diversity Arguments and the Fate of the Black Corporate Bar' (2004) 117 Harvard Law Review 1548.

${ }^{22}$ n 5 above, [26].

${ }^{23} \mathrm{n} 6$ above, [70].

${ }^{24}$ For an even more detailed position on the issue, see Thomas n 1 above, 57-58.
} 
concept of justice itself., ${ }^{25}$

My contention is that one's position on the importance of diversity will depend to a great extent on one's view of the nature of adjudication. It is reasonable to expect that people with different views on adjudication will assign diversity different weights. However, I also claim that no plausible view of what judges are doing is consistent with the position that diversity has no epistemic value. I will discuss the epistemic benefits of diversity under three headings.

The diversity of legal expertise. The discourse on judicial diversity often neglects the importance of professional diversity. The reason for this may be that there is not always a strong correlation between the diversity of legal expertise and social diversity. One can easily imagine, for example, a professionally more diverse UK Supreme Court without necessarily changing the social make-up of the institution. However, since I am more interested in cognitive than social diversity, the diversity of legal expertise is directly relevant to my argument.

The appointment process itself takes into consideration one type of professional diversity. According to section 27(8) of the CRA, 'in making selections for the appointment of judges of the [Supreme] Court the commission must ensure that between them the judges will have knowledge of, and experience of practice in, the law of each part of the United Kingdom.' Although this practice might have other than epistemic justifications (I find the argument from public confidence very relevant here), ${ }^{26}$ the Act seems to justify the above requirement entirely on epistemic grounds: the candidates do not have to be, for instance, Scottish, but have to be familiar with Scots law.

If expertise in the law of different jurisdictions is important, it is unclear why the

\footnotetext{
25 ibid.

${ }^{26}$ As Alan Paterson and Chris Paterson put it, "This requirement is designed to ensure that there is continued representation from both Scotland and Northern Ireland on the Supreme Court." Paterson and Paterson n 1 above, 26. However, the provision in question speaks only about expertise on Scots law and not the representation of Scotland.
} 
expertise in different areas of law would be irrelevant. One could argue that the aforementioned example is misleading since English and Scottish candidates do not compete with each other but compete for two differently defined positions. Just like a goalkeeper in a football team, or a conductor in an orchestra, Scottish justices have a specific job description that is slightly different from that of the other members of the group. When one of the two positions for Scottish justices becomes vacant, the selection committee is required to choose the most competent candidate among the ones who have the requisite expertise in Scots law. However, in many cases we do not have such fixed roles within a group and, therefore, have to advance diversity among people who compete for the same position. For instance, there is not a separate position in the Supreme Court for criminal lawyers or international lawyers. But it does not mean that their special expertise would not be an epistemic asset for the court. If that is true, competence and diversity might pull in different directions when lawyers with different expertise compete for the same position.

The diversity of life experiences. It is a truism that in the adjudicative process judges have to apply legal rules to the facts of a particular case. This process requires judges to understand complex factual situations, the significance of facts and also causal mechanisms between certain states of affairs. I wholeheartedly agree with the statement quoted above from the Report of the House of Lords Select Committee on the Constitution that judging is a complex activity. This complexity explains why the relevance of cognitive diversity cannot be limited to the diversity of legal expertise.

I believe that a case often cited in the literature brings home this point very nicely. In Safford Unified School Dist. \#1 v Redding, ${ }^{27}$ the US Supreme Court addressed the question of whether the Fourth Amendment to the US Constitution prohibits school officials from stripsearching students suspected of possessing drugs in violation of school policy. Many

27557 U.S. 364 (2009) 
commentators noticed that the judges had strikingly different attitudes towards the stripsearch of a 13-year-old girl during the oral hearing. It was Justice Ginsburg, then the only female member of the court, who explained to her male colleagues why strip-searching constitutes a harm that is constitutionally relevant. As she said about her male colleagues to USA Today, 'They have never been a 13-year-old girl. . . . It's a very sensitive age for a girl. I didn't think that my colleagues, some of them, quite understood. ${ }^{28}$ The important point here is that Justice Ginsburg's distinctive cognitive toolkit helped the court to make a better (or at least more informed) decision. However, her special contribution had nothing to do with her legal expertise. Rather, it was related to her better understanding of the moral significance of certain facts (why strip-searching causes moral harm). And since the law itself made the moral significance of those facts legally relevant, Justice Ginsburg's knowledge helped the court to reach a decision that is not only morally but also legally better than its alternative. $^{29}$

This case also supports two additional points. First, we should commend the male justices who listened to Justice Ginsburg for their openness. This is a nice illustration of the quality that the JAC calls 'an ability to understand' or the 'ability to treat everyone with respect and sensitivity whatever their background.' However, as the case illustrates, the ability to understand the experience of other people is not the same as having the same experience for oneself. A good decision, in that case, required both someone having the relevant experience and others having the ability to understand that experience.

Second, this case also illustrates that the diversity of life experiences can be relevant

\footnotetext{
28 J. Biskupic, 'Ginsburg: Court Needs Another Woman' USA today (5 October 2009) <http://usatoday30.usatoday.com/news/washington/judicial/2009-05-05-ruthginsburg_N.htm>.

${ }^{29}$ For evidence that race also shapes how judges interpret social reality, see S.A. Ifill, 'Racial Diversity on the Bench: Beyond Role Models and Public Confidence' (2000) 57 Washington and Lee Law Review 405; R. Delgado and J. Stefancic, 'Norms and Narratives: Can Judges Avoid Serious Moral Error' (1990) 69 Texas Law Review 1929.
} 
not only in exceptionally hard cases when we run out of legal rules. ${ }^{30}$ It can become important in every single case when we subsume the facts of the case under a general rule.

The general importance of cognitive diversity. The case for the epistemic importance of diversity is further corroborated by studies from other fields. ${ }^{31}$ Although judicial decisionmaking certainly has its own distinctive characteristics, there are also many features that it shares with other forms of decision-making. It would be narrow-minded legal parochialism to ignore the relevance of this literature to judicial decision-making. ${ }^{32}$ To make the trivial point, judges are also human beings. As such, they are not immune to certain cognitive biases or motivational failures. ${ }^{33}$ Judges also rely on powerful cultural narratives to describe and make sense of social reality. ${ }^{34}$ Although as the JAC criteria make clear, 'an ability to understand' is an important judicial virtue, psychological research shows that even the most open-minded and intelligent people are vulnerable to what is called the confirmation bias. ${ }^{35}$ People tend to seek and interpret evidence not simply in light of, but also to confirm, their existing beliefs. We can counteract the distortive effects of the confirmation bias more effectively by a diverse judiciary than by relying on the open-mindedness of judges.

\footnotetext{
${ }^{30}$ In my view, the Report on the Advisory Panel on Judicial Diversity underestimates the importance of diversity by focusing on judicial discretion. As the Report says, This [the diversity of perspectives] is particularly important where there is scope for the exercise of judicial discretion or where public interest considerations are a factor. See $\mathrm{n} 5$ above, [26].

${ }^{31}$ The most directly relevant studies are arguably those that are dealing with the importance of diversity in political decision-making. See, for instance, H. Landemore, Democratic Reason: Politics, Collective Intelligence, and the Rule of the Many (Princeton: Princeton University Press 2013); H. Landemore and J. Elster (eds), Collective Wisdom: Principles and Mechanisms (Cambridge: CUP 2012).

${ }^{32}$ For the very same reason, the argument that is developed in the present paper also has implications far beyond the issue of judicial appointments. However, the question of to what extent it can be transferred to other legal contexts would require contextual analysis that is beyond the scope of the present article. To briefly illustrate this point, the diversity of student bodies has been a central issue in American affirmative action cases.

However, there are salient differences between the student body of a university and a high court, such as the UK Supreme Court. For instance, although a more diverse student body is an epistemic asset, the members of a student body do not have to act together as do the members of a court. The argument about problem solving then applies only to situations where the members of the collective have to find a solution to an issue by acting together. This example shows that although some arguments for diversity apply to both cases, my conclusion about judicial diversity cannot be automatically transferred to other contexts. The difference emphasised above might tip the balance of arguments differently in the two cases, even if diversity is relevant in both contexts.

${ }^{33}$ C. Guthrie, J.J. Rachlinski and A.J. Wistrich, 'Blinking on the Bench: How Judges Decide Cases' (2007) 93 Cornell Law Review 1.

${ }^{34}$ For the role of cultural narratives, see R. Delgado, 'Storytelling for Oppositionists and Others: A Plea for Narrative' (1989) 87 Michigan Law Review 2411.

${ }^{35}$ R.B. Mahzarin and A.G. Greenwald, Blindspot: Hidden Biases of Good People (New York: Bantam 2016).
} 
I find Scott E. Page's findings particularly relevant for assessing the relevance of diversity. Page first developed an agent-based model, a computer simulation program that social scientists often use to study complex and dynamic social systems to examine how a group of agents with different cognitive toolkits solve problems together. ${ }^{36}$ The agent-based model systematically generated the counterintuitive outcome that a diverse group of agents outperforms a homogeneous group even if the latter consists of individually more able agents. Later he is his colleague gave a formal mathematical proof of this insight. ${ }^{37}$ Their central claim is that as far as problem-solving is concerned, under some non-unrealistic conditions, 'if we have two groups of problem-solvers of equal individual ability, one of them is homogeneous, and the other is diverse, then the diverse collection will, on average, outperform the homogeneous collection.' 38

The gist of their explanation is that in problem-solving, a group of homogeneous problem-solvers will be stuck at the same place, and therefore the group cannot perform better than the best individual in the group. By contrast, if people have different perspectives or heuristics, it is likely that they will come up with individually different optimal solutions. In that case, by acting together one can improve on others' optimal solution. This improvement means that the group as a whole can perform better than the best member of the group. ${ }^{39}$

It is important to emphasise here that Page does not offer empirical proof that a collection of random people outperforms the collection of the best people under certain

\footnotetext{
${ }^{36}$ For agent based modelling in general, see N. Gilbert, Agent-Based Models (Quantitative Applications in the Social Sciences) (Los Angeles: SAGE 2007); R.A. Axelrod, Complexity of Cooperation: Agent-Based Models of Competition and Collaboration (Princeton, N.J.: Princeton University Press 1997); J.M. Epstein and R.L. Axtell, Growing Artificial Societies: Social Science from the Bottom Up (Complex Adaptive Systems) (Washington D.C.: The Brookings Institution Press 1996).

${ }^{37}$ L. Hong and S.E. Page, 'Groups of Diverse Problem Solvers Can Outperform Groups of High-Ability Problem Solvers' (2004) 101 Proceedings of the National Academy of Sciences of the United States of America 16385.

${ }^{38} \mathrm{n} 15$ above, 157.

39 The argument from better problem-solving is also part of what is usually called the „,business case for diversity". See, for instance, Wilkins n 21 above, 1576.
} 
conditions. Rather, his analysis provides a formal mathematical proof that his theorems apply to the mathematical representations of cognitive toolkits. Empirical research cannot be applied directly to the agents of computational models, but only to human beings who also possess diverse cognitive toolboxes. But once we understand the logic of diversity, as Page calls it, we are also better equipped to ask the proper empirical questions. For instance, even if a group is socially diverse, we cannot expect the benefits of cognitive diversity if the members of the group do not have different cognitive tools. Similarly, we cannot expect that a more diverse group will outperform a homogenous one if their job is not problem-solving (or prediction), or the members of the group do not cooperate.

Justice Ginsburg's example in Safford Unified School Dist. \#1 v Redding provides a good illustration of this theory. Her special contribution in the case cannot be explained by her above average competence. She could have contributed to the decision-making with something special, even if her competence had been below average. Her unique contribution, in that case, was more useful for the court as a whole than an additional male judge's contribution could have been, even if the latter had been more competent than her.

In light of the aforementioned arguments, the simple view seems untenable. If the conclusion of the simple view, the Equal Merit Principle, is appealing, it is not appealing because diversity is not an epistemic asset, but for a different reason.

\section{Competence always trumps diversity}

The second possible argumentative strategy preserves the first two tenets of the simple view. It adheres to the Performance Maximising Principle and also claims that non-epistemic considerations should not compete with epistemic ones. However, it gives up the third tenet of the simple view and concedes that cognitive diversity has epistemic value.

But how is it possible to hold simultaneously (1) the Performance Maximising 
Principle, (2) the epistemic significance of diversity, and (3) the Equal Merit Principle? There is only one way to reconcile these three theses: one has to establish that although diversity is an epistemic asset, judicial competence always trumps diversity in the epistemic dimension. To put it otherwise, the Performance Maximising Principle itself requires a strict lexical order between judicial competence and diversity; that is, it requires us to maximise judicial competence before we move on to increase diversity. ${ }^{40}$

Although it is theoretically possible to defend the Equal Merit Principle this way, there are no scholarly works widely available that pursue this strategy. If one concedes that diversity is an epistemic asset, it seems to be a very counterintuitive position to hold that no gain in diversity (no matter how big this gain is) can ever compensate for the smallest possible loss in judicial competence. It is not sufficient for the advocates of the Equal Merit Principle to prove that judicial competence is generally a more important epistemic asset than diversity. What they must establish is that no trade-off between these two considerations can ever be justified.

However, this position seems to be not only counterintuitive and unsubstantiated by the advocates of the Equal Merit Principle, but also wrong. Scott E. Page has also convincingly demonstrated that as far as problem-solving is concerned, under certain nonunrealistic conditions, diversity is more important than individual ability. As his Diversity Trumps Ability Theorem says: 'a randomly selected collection of problem solvers outperforms a collection of the best individual problem solvers' ${ }^{41}$ But diversity may also trump ability, even if not all the conditions are met. The previous subsection has already shed light on why a diverse group can outperform less diverse ones, even if the average competence of the latter group is higher: by acting together the members of the diverse group can improve on the optimal solutions of the other group members. By contrast, a

\footnotetext{
${ }^{40}$ I borrow the concept of lexical order from Rawls. See J. Rawls, A Theory of Justice (Oxford: OUP 1973) 4243.

${ }^{41}$ n 15 above, 162.
} 
homogeneous group cannot perform better than the best member of the group, since their optimal solutions will be very similar.

\section{Justice always trumps epistemic performance}

The argument of my paper has reached an important juncture here. I have assumed so far that judicial competence is important because it contributes to the epistemic performance of courts. If neither of the above strategies managed to justify the Equal Merit Principle, we have no other option but to admit that the Equal Merit Principle is inconsistent with the Performance Maximising Principle. If the Equal Merit Principle is attractive, its appeal cannot be that it maximises the epistemic performance of courts. The advocates of the principle have to establish that it is attractive despite the fact that it can lead to epistemically suboptimal results.

At this point, I am claiming only that the advocates of the Equal Merit Principle must offer some non-epistemic argument in defence of the principle; I am not claiming that there is only one logical possibility to do that. However, since they do not usually articulate nonepistemic arguments in support of the principle, all I can do here is to engage with a line of non-epistemic argument that, in my view, provides the strongest support to the Equal Merit Principle. I will call this approach the argument from desert.

When we appoint judges, we allocate very important and highly valued goods (judicial offices) among competing candidates. In the allocation of judicial offices, we require the government to act justly. The third argumentative strategy suggests that competence gives us guidance concerning what justice requires in the judicial appointment process. We should appoint the most competent candidates not because this maximises the epistemic performance of the courts, but because they are the ones who deserve to be appointed. Acting justly in this context means that we give every candidate his/her due. If Amy is more competent than 
Bella, Amy deserves to be appointed, and it would be unjust if we selected Bella.

My contention is that although this argument is based on a particular conception of justice and not the instrumental role of competence, it is also parasitic on the Performance Maximising Principle. Therefore, once one admits that a purely competence-based system does not maximise epistemic performance, the argument from desert is also fatally undermined. Let me substantiate this claim.

The principle of formal justice requires us to treat like cases alike. However, it leaves open the question of 'likeness'. Therefore, we need to add substantive considerations to the formal principle of justice that determine the criteria of relevant similarity. In the context of the judicial appointment process, this means that we make assumptions about the function of the institution and define the relevant qualities in light of this function.

A good knife should be able to cut. Therefore, the primary virtue of a knife is being sharp. It can have other virtues, but so far as it cannot cut, it is not a good knife. Similarly, a good football team has to win matches. Although one should commend the team if it helps social mobility, and praise players if they serve as role models for young kids, these are not the primary qualities by which players should be selected. Following this train of thought, the primary virtue of a good court is that it makes correct decisions. Although it is fortunate if the judicial appointment process increases the public confidence in courts, or gives opportunities to previously disadvantaged groups and improves social mobility, these considerations are secondary and external to the primary task of a court.

The argument from desert, as I formulate it, derives its force from a particular view on the function of courts and how this function distinguishes between relevant and irrelevant qualities. The argument runs as follows: (1) The primary task of courts is to make correct decisions; (2) When judicial offices are allocated, only those qualities should be taken into account (or those qualities should have primacy) that are relevant for fulfilling the primary 
function of the court; (3) Competence is the only quality that is relevant for the primary function of the court. (4) If two candidates are not equally competent, justice requires us to appoint the more competent candidate. (5) If two candidates are equally competent, diversity can be used as a tiebreaker.

The whole purpose of the previous analysis was to point out that even if we accept the premise of the argument that the selection process must maximise the epistemic performance of the court, competence is not the only consideration that is epistemically relevant.

To further develop my argument, let me introduce a distinction that, in my view, should play a crucial role in the debate. I will use a thought-experiment for that purpose. Let us suppose that our challenge is to create the strongest possible court that consists of 12 judges. In addition, let us assume that there is a broad consensus in the community that Amy is the most competent candidate. Finally, let us imagine that Amy can be easily cloned. Since Amy is the most competent candidate, we should definitely build the court around Amy. It is also plausible to claim that it would be good to have more clones of Amy on the court. However, the interesting question is whether we should populate the whole court with the clones of Amy. If cognitive diversity is an epistemic asset, we should answer this question in the negative. Even if Amy is, ex hypothesi, the most competent candidate, populating the court with her clones would not maximise the epistemic performance of the institution. We do not have to agree on how many clones of Amy would be optimal to have, as it is enough for our purposes to accept that at some point a judge with a different skill set would be more valuable for the court than an additional clone of Amy.

This constructed example shows that one can evaluate a judge by two different criteria. Competence ranks the candidates in absolute terms. To answer the question of who the most competent judge is, let me offer a formal test: the most competent judge is the one who should be selected if the court consisted of only one member. In that case, the 
Performance Maximising Principle would always require us to select the most competent judge. However, the same logic does not apply if we build a multi-member institution. The second criterion, let us call it contribution, is a positional one; it is determined not only by the judge's own competence, but also by the composition of the court, and the skill set of the other judges. ${ }^{42}$ The fact that Amy is more competent than Bella does not imply that her appointment will always maximise the epistemic performance of the court. Conversely, the fact that at some point we are justified in preferring Bella to Amy does not make Bella a more competent judge than Amy.

If one equates merit with competence and, therefore, automatically attaches moral consequences to competence, they will easily jump to the conclusion that the most competent judge, in our example Amy, deserves to be appointed. However, the above argument shows that in those cases when Bella contributes more to the epistemic performance of the court than Amy, her appointment is based on considerations that are clearly relevant to the primary function of courts. In those cases, therefore, Bella deserves to be appointed. One might say that Amy is unlucky if her superior competence does not translate into superior contribution. She is unlucky because if the composition of the court had been slightly different, she could have been the one who is selected. However, this is not the same as saying that under such circumstances she is the one who deserves to be appointed.

Let us assume that my argument is wrong and Amy does indeed deserve to be appointed, even if Bella could contribute more to the epistemic performance of the court. The advocates of the Equal Merit Principle would still have to face two difficulties. First, since they make a concession and are ready to balance epistemic performance against nonepistemic considerations, the principle of desert should compete with other, rival interpretations of justice, like the second version of the argument from equal opportunity. The

\footnotetext{
${ }^{42}$ Alan Paterson and Chris Paterson call this the corporate competence of the institution. Paterson and Paterson n 1 above, 48 .
} 
proponents of the Equal Merit Principle could no longer dismiss the competing conceptions of justice on the basis that they compromise epistemic performance, as their favoured principle would do exactly the same.

Second, the Equal Merit Principle asks us not simply to balance desert against epistemic performance, but to give lexical priority to the former. According to the argument from desert, justice should prevail no matter how much we compromise the epistemic performance of courts. But the advocates of the principle do not explain why desert should always trump epistemic performance.

Before turning to an alternative to my critique, I will conclude this section by spelling out an implication of my position. I rejected both the argument that competence should be the only criterion of judicial selection and that competence should always trump diversity or diversity should act as a tiebreaker. What role should competence play in the appointment process? One possibility is that competence should be treated as a threshold criterion. ${ }^{43}$ The selecting body must not appoint anybody who is below a certain standard. However, it does not always have to appoint the most competent candidate either. The threshold approach is fundamentally correct, but not precise enough. If it means that above a certain threshold of competence the appointing body should aim at maximising diversity, the threshold principle

will produce suboptimal outcomes in a subclass of cases. The threshold principle, therefore, should not be used to maximise diversity. Rather, the selecting body should have the discretion to choose the candidate who most ideally balances competence and diversity.

\section{The Critique of the Merit in Diversity Principle}

In her book on judicial diversity, Erika Rackley mounted a sophisticated challenge to the

\footnotetext{
${ }^{43} \mathrm{n} 6$ above, [95]-[97].
} 
simple view on judicial appointments that significantly differs from my argument. ${ }^{44}$ She contends that those who challenge the simple view can follow three different argumentative strategies. First, they can admit that diversity is different from merit and challenge the merit principle directly. According to this strategy, merit is important, but there are other considerations that the appointment process should also take into consideration (Merit, dislodged). Second, they can argue that we should redefine the concept of merit since merit reflects the expectations of the present members of the judiciary and that this helps the judiciary to replicate itself (Merit, distorted). Finally, her own position claims to eliminate the conflict between merit and diversity. As she says, 'merit and diversity stand and fall together' (Merit in diversity). ${ }^{45}$

Her position entails three important claims: (1) diversity is an important epistemic asset; (2) merit and diversity always pull in the same direction; (3) judges should be appointed solely on the basis of merit. Rackley is clearly right to criticise the simple view that rejects her first thesis. As my whole argument testifies, I completely agree with her on that issue.

However, her second thesis misconstrues the relationship between merit and diversity. She says that "we are no longer faced with having to choose between advancing diversity and appointment on merit. Arguments for judicial diversity grounded in its contribution to the quality of judicial decision-making and arguments for appointment on merit point in the same direction. ${ }^{46}$

This position has two important weaknesses. The more fundamental one is that Rackley fails to distinguish between the two evaluative perspectives that I called competence and contribution, respectively. She conflates the question of the best judiciary with that of the best judge. 'If we want the best possible judiciary, if we want a judiciary that is comprised of

\footnotetext{
${ }^{44}$ E. Rackley, Women, Judging and the Judiciary (Abingdon: Routledge 2014) 187-197.

45 ibid, 195.

${ }^{46}$ ibid, 194-195.
} 
individuals who are (on any view) the best, then we must also be committed to ensuring (among other things) that they are drawn from as varied and diverse backgrounds as possible. ${ }^{47}$ However, this position does not do justice to the complexity of the problem we face. If we recall the story of Amy and Bella, Amy would be justified to claim that she is the better candidate, even if Bella could contribute more to the court's performance. Rackley's position cannot explain why Amy is justified in feeling unlucky and disappointed if Bella is appointed. Amy would be disappointed since she was rejected not because she lacked competence, but because of something that is entirely beyond her control: the competence of the other judges determines the value of her contribution to the court as an institution.

More importantly, in the harmonious world envisaged by Rackley's theory, the conflict between competence and diversity is not addressed directly. However, by making diversity a component of merit, that conflict does not disappear but is only reproduced within the criteria of merit. Individual competence and the diversity of the group can conflict even if they are both the components of merit, and this potential conflict must be at the heart of every sophisticated theory of judicial selection and must be addressed head on.

The second problem follows directly from the first one. By ignoring the potential conflict between competence and diversity, Rackley does not realise that contribution, or what she calls merit, is a function of individual competence and collective diversity. She is correct to claim that, other things being equal, diversity contributes to the epistemic performance of courts. However, since contribution (or in her terminology, merit) is a function of diversity and competence, it does not follow that a more diverse court always outperforms a less diverse one. To put it differently, diversity and merit do not stand and fall together.

Rackley's theory is in a certain sense the mirror image of the simple view on judicial

47 ibid, 195. 
appointments: neither of them admits the need for a trade-off. In order to maximise the epistemic performance of a court, the simple view instructs the selectors to maximise the competence of individual judges. According to the simple view, diversity cannot be balanced against judicial competence. By contrast, Rackley’s theory suggests that diversity does not have to be balanced against any relevant consideration. If that were true, we would maximise the epistemic performance of a court by maximising diversity. But this is simply not the case. Since there is a trade-off between individual competence and diversity, in some cases competence will trump diversity. In these cases, advancing diversity is detrimental to the overall epistemic performance of the court and the average contribution or merit of individual judges. The harmonious world Rackley envisages is, unfortunately, not a real option.

I want to make clear at this point that I do not have strong theoretical objections to redefining merit per se and equating it with contribution instead of competence. As long as we keep in mind that contribution is a function of competence and diversity and that there is a trade-off between these two considerations, there is no inherent danger in this conceptual strategy. There is no practical difference between saying that (1) judges should be appointed on the basis of merit (understood as contribution); (2) the appointment procedure should take into consideration both merit (understood as competence) and diversity. My preference for the second approach is justified simply by linguistic conventions. It seems that competence is closer to our ordinary understanding of merit. The Report of the House of Lords Select Committee on the Constitution reflects this opinion. ${ }^{48}$

This attitude is expressed most clearly by Lord Carswell's comment on diversity. On interpreting diversity as an aspect of merit, he advises to: 'take it into account, but do not call

\footnotetext{
${ }^{48} \mathrm{n} 6$ above, [89]-[94]. For another position that diversity should be considered an aspect of merit, see Thomas $\mathrm{n}$ 1 above, 55. I am ready to admit that the strategy that makes diversity a component of merit might have a better chance of endorsement by the relevant decision-makers since in that case they could insist that judges are appointed solely on the basis of merit. However, this question is beyond the scope of present paper.
} 
it merit. ${ }^{49}$ The Equal Merit Principle itself illustrates this understanding. Diversity can be a tiebreaker between equally meritorious candidates only if merit and diversity are distinct concepts. According to Rackley's approach, the Equal Merit Principle is not wrong, but conceptually confused. The Equal Merit principle assumes the intelligibility of a two-stage procedure: in the first step, we determine the merit of the candidates. If they are equally meritorious, we can select the candidate who makes the court more diverse. However, if diversity is an aspect of merit, by choosing the candidate who makes the court more diverse, we also increase the merit of that candidate. Therefore, the two candidates were not of equal merit in the first place.

\section{Qualifying the argument}

In the rest of my paper, I address three potential objections to my position and fine-tune the argument accordingly. As I argued above, the significance one attributes to diversity is likely to be influenced by one's view on the nature of the adjudicative process. Accordingly, my argument also makes some assumptions about the nature of the judicial work. Each objection I will address in this section challenges a hitherto unstated assumption of my position. To defend that position, I must establish that the assumptions behind my argument are correct, or at least more plausible than the alternatives.

\section{Judging is a solitary process}

The first objection says that my account fundamentally misunderstands the nature of the judicial process. The argument to the effect that cognitive diversity matters is predicated on the idea that judges work together as a team. However, so the argument runs, judging is better characterised as a solitary exercise. The decision of a court is fundamentally different from

\footnotetext{
${ }^{49} \mathrm{n} 6$ above, [93].
} 
the performance of a football team or an orchestra where the players or the members of the orchestra act together. Judges do not act together in the same way. When we are speaking about the decision of a court, we simply aggregate the votes of individual judges.

Aggregating judicial votes does not require judges to form their opinion together. If that is correct, we maximise the epistemic performance of the court by maximising the competence of individual judges.

Although I emphasised the importance of problem-solving for judicial decisionmaking, and as far as problem-solving is concerned, judges indeed can profit from the benefits of diversity only if they act together, some benefits of cognitive diversity do not assume this strong form of collective action. An epistemically diverse group of people, for instance, makes more accurate predictions than a homogeneous one, even if the prediction of the group is simply the aggregation of individual predictions. ${ }^{50}$

More importantly, I believe that the above description of judicial decision-making is highly unrealistic and that judging is a much more collective enterprise than the aggregative view suggests. Even if the final responsibility for an opinion lies with the individual judge, they are still confronted with the opinion of the other members of the panel. As Alan Paterson's excellent book on the UK Supreme Court demonstrates, many of the justices consider themselves team-players who act together to solve difficult legal issues. ${ }^{51}$ It is true that some justices have a more individualistic approach to adjudication. But it is worth keeping in mind that even this individualistic approach only implies that those justices are less keen to influence their colleagues or to lobby for their own position than the less individualistic judges. ${ }^{52}$ It does not follow that these justices are not open to the arguments of their colleagues and are not ready to learn from them, and this is all we need to establish here.

\footnotetext{
${ }^{50} \mathrm{n} 15$ above, 205-212.

51 A. Paterson, Final Judgment: The Last Law Lords and the Supreme Court (Hart Publishing 2013) 130-135, 141-145; H.T. Edwards, 'The Effects of Collegiality on Judicial Decision Making' (2002) 151 University of Pennsylvania Law Review 1639.

${ }^{52}$ Paterson n 51 above, 131.
} 
In addition, the benefits of judicial diversity can derive not only from dialogue with other judges of the same panel (for the sake of convenience, let me call this dialogue internal.) Judges also engage with the opinions of the members of other courts (e.g., other domestic courts, foreign courts and international courts) and also with former members of the same court (these dialogues I will call external). It seems entirely unrealistic to assume that a judge would not learn from the opinions of others. If the judiciary as a whole is more diverse, each judge can profit from this diversity, even if a particular panel is relatively homogeneous.

\section{Reasonable disagreement}

Second, others could insist that I misunderstand the nature of judicial decision-making, albeit for reasons that are different from the ones suggested by the first objection. My argument for cognitive diversity assumes that judges engage in problem-solving and that any problem has one correct or right solution. However, this misrepresents the nature of legal dilemmas. Finding the cure for ebola, for instance, is a complex problem, but the criteria for success or failure are quite clear. Although judges also address complex issues, most of them, like the interpretation of abstract, value-laden human rights provisions, do not have one right answer. In these kinds of cases, a judge's decision will reflect his or her values. The fact that more judges prefer one interpretation of an abstract, value-laden rights provision than another does not prove that the result preferred by the majority is more rational than the one preferred by the minority.

The court's decision will provisionally close the debate, but the outcome of the decision is not a 'solution' in the same sense as a medicine is a solution to a medical problem, or a mathematical proof is a solution to a mathematical conjecture. Although my argument so far has not taken into account the fact of reasonable moral disagreement, I do not believe that this undermines my position. On the contrary, it lends further support to it: it makes diversity 
not less, but much more important. ${ }^{53}$

Controversial moral questions that are at the heart of many legal cases - human rights adjudication is the most obvious example - usually have more than one reasonable solution. The idea of reasonable disagreement does not assume that moral propositions cannot be true or objective. It claims only that most of our moral claims are inconclusively justified. A person with different experiences from mine can reasonably reject some of my moral claims even if I, building on my own experience, have good reasons to accept them. As Lord Sumption says in the legal context:

No I don't [think there is a single right answer in each appeal], I think there certainly is in some cases. I think that there may be a variety of satisfactory answers which are satisfactory to different degrees from different points of view and obviously a lot depends on your basic instinct, which is likely to colour your approach to cases generally which are the most important considerations. ${ }^{54}$

My contention is that the fact of reasonable disagreement has far-reaching implications for the issue of judicial diversity. If we accept that in many cases judges face such dilemmas, we have to admit that the judicial process adjudicates between reasonable but inconclusively justified moral beliefs. In such cases, the importance of diversity does not derive from the fact that judges - cooperating with one another - are more likely to find the correct solution. But it would also be a mistake to conclude that in such cases diversity is important only because it increases the confidence of the public in the judiciary.

In such cases, there is a more complex relationship between epistemic considerations

\footnotetext{
${ }^{53}$ Many works on judicial diversity emphasise that the importance of the different perspectives held by different people without explaining in detail why having different perspectives is useful. The argument here is that the difference of perspectives is important both when (1) a case is complex, but it has one correct solution, and (2) when all we have are different reasonable, but inconclusively justified, views. However, the importance of diversity requires separate explanations in the two cases.

${ }^{54}$ Quoted by Paterson $n 51$ above, 272.
} 
and the legitimacy of judicial decision-making than my theory so far admits. Within the confines of this article, I cannot provide a sufficiently nuanced analysis of this relationship but, hopefully, can substantiate the claim that we have additional reasons to cherish diversity. ${ }^{55}$

First, if on a controversial moral issue there are many reasonable but inconclusively justified positions, fairness requires that a wide range of positions be represented in the deliberative process. ${ }^{56}$ The argument from public confidence puts the emphasis on how the public perceives the judiciary and judicial decisions. However, it is not enough that the public accepts such decisions ex ante; their views should also be reflected in the decision-making process itself. On controversial moral questions judges do not have special expertise, and their views on such questions, similar to the views of many other people, are likely to be reasonable but not conclusively justified. Therefore representing a wide range of moral positions in judicial decision-making is important even if we cannot expect that judges cooperating with each other - will find the correct solution.

Second, even in modern, pluralist societies where we disagree on many issues, it is conceivable that at least some moral principles are publicly justified, that is, justified to all members of the society. My contention is that such publicly justified principles have stronger legitimacy than those that can be justified only to a segment of society. If this is correct, political institutions should at least aim at justifying their authoritative decisions by appealing to publicly justified principles. To put it differently, they must be capable of tracking those principles. However, an institution that is not diverse enough cannot lay a claim even in principle that it is capable of doing that.

Third, even in those cases where we cannot hope that the truth will come to the

\footnotetext{
${ }^{55}$ For a more detailed analysis of the issue, see T. Gyorfi, Against the New Constitutionalism (Elgar Monographs in Constitutional and Administrative Law Series) (Cheltenham: Edward Elgar Publishing 2016) 42-62, 125-132.

${ }^{56}$ See Thomas n 1 above, 62-63; Ifill n 29 above.
} 
surface through discussion, or when it is impossible to find publicly justified principles, the presence of different reasonable positions has crucial epistemic significance: it tends to make those views more reflective. As Mill's classic argument pointed out, without robust dissent even the views that are true can degenerate into dead dogmas. ${ }^{57}$ There is empirical evidence that when there is a 'different voice' in a judicial panel, for instance, a judge from a minority background, the dynamics within the panel changes and judges will be willing to consider a broader array of considerations. ${ }^{58}$ Dissenting opinions can force the judges in the majority to clarify points that they might have previously regarded as unproblematic or that they might have left unarticulated. They may also recognise the need to engage with arguments that they had not otherwise considered. This process improves the quality of arguments even if the process ends with each party remaining unconvinced by the arguments of the other.

The upshot of this is that the presence of different perspectives within the judiciary not only (1) makes judges better problem solvers but (2) is also important because of the considerations of fairness. In addition, diversity (3) is a precondition of tracking publicly justified moral principles, and (4) makes the rival moral positions more reflective.

\section{The fallacy of composition}

Let me remind the reader of the thought experiment that I suggested above. It was about creating the strongest possible court that consisted of 12 judges. If my argument is correct, we need a diverse court to maximise the epistemic performance of that institution. If the court sits en banc, the epistemic capacity of the institution is the same as the epistemic capacity of the judicial panel that delivers the decisions. That means that the logic of my argument

\footnotetext{
57 J. S. Mill, On Liberty. (London: ElecBook 2001) 57-66.

58 Thomas n 1 57-60; J.P. Kastellec, 'Racial Diversity and Judicial Influence on Appellate Courts' (2013) 57 American Journal of Political Science 167; D.R. Songer and K.A. Crews-Meyer, 'Does Judge Gender Matter? Decision Making in State Supreme Courts' (2000) 81 Social Science Quarterly 750; S.B. Haire and L.P. Moyer, Diversity Matters: Judicial Policy Making in the U.S. Courts of Appeals (Constitutionalism and Democracy) (Charlottesville - London: University of Virginia Press 2015).
} 
applies, for instance, to the US Supreme Court or the French Constitutional Council. However, it does not necessarily apply to the UK Supreme Court or the German Constitutional Court which sit in panels that do not comprise all judges of the court.

Let me use again my thought-experiment to clarify this point. My argument was that although Amy is more competent than Bella, at a certain point, depending on the composition of the court, Bella can contribute more to the epistemic performance of the court than Amy. In that case, it is justified to appoint Bella and Bella deserves to be appointed. It is important to keep in mind, however, that Bella's contribution to the epistemic performance of the court was determined partly by, and contingent on, the cognitive toolkit or skillset of the other members of the court. Hence, it can happen that Bella contributes more to the epistemic performance of the whole court than Amy, but in some cases, given the skills of the four other justices, it would be Amy who could maximise the performance of a particular panel of five justices and not Bella.

This objection forces me to admit that my argument does not apply straightforwardly to all courts. The smaller the number of judges sitting in a panel, the weaker my argument becomes. However, I still maintain that the Equal Merit Principle is unattractive even in those cases where judges sit in relatively small panels, or the decision is made by a single judge. My position rests on two considerations. First, the above objection focuses exclusively on how judicial diversity affects the internal dialogue among the judges who actually sit in a particular case. But as I argued above, judges can also draw on the insights and arguments of other judges who are not involved in the pending case.

Second, the objection proves only that the optimal trade-off between competence and diversity will be slightly different depending on whether we are supposed to maximise the epistemic performance of the whole court, or only a panel of it. One could argue that the smaller the panel is, the more important competence becomes as compared to diversity. 
However, the Equal Merit Principle would surely generate suboptimal results, since it does not allow us to make any trade-offs between competence and diversity. If we have to choose between a principle that never allows us to balance competence against diversity and one that permits such trade-off but sometimes can lead to suboptimal results, we should choose the latter.

\section{Conclusion}

In the introduction, I claimed that the 'Solely on Merit Principle' is either wrong, for the very same reasons as the Equal Merit Principle, or rather uninformative since it fails to give sufficient guidance to those who select judges.

I argued above that diversity is an important epistemic asset and, therefore, appointing judges solely on the basis of merit, if merit is understood as the competence of the individual judge, is simply wrong. Although the proponents of the simple view contend that deviating from a purely competence-based appointment system would undermine the quality of the judiciary, the opposite is true: a purely competence-based system cannot be justified on epistemic grounds.

If merit is understood as a function of the competence of an individual judge and the cognitive diversity of the court as a whole, then it is correct to say that judges should be appointed on merit. However, in that case, a judgment on merit simply reflects the outcome of a balancing exercise, but merit itself does not tell us anything interesting about the process of balancing. Competence and diversity are both important to maximise the epistemic performance of courts and finding the optimal trade-off between them should be at the heart of every sophisticated theory of judicial appointments. 